\title{
MENINGKATKAN AKTIVITAS BELAJAR, PEMBELAJARAN, DAN HASIL BELAJAR PPKn SISWA KELAS VIII SMP NEGERI 1 BINONGKO MELALUI MODEL PEMBELAJARAN KOOPERATIF TIPE JIGSAW
}

\author{
Muhammad Kasim, Hamuni, Wa Ode Hijrah \\ Jurusan Pendidikan Pancasila dan Kewarganegaraan \\ Fakultas Keguruan dan Ilmu Pendidikan \\ Universitas Halu Oleo \\ Email.muhammadkasim@gmail.com, \\ hamunifaturrahman@gmail.com,hijrahwaode207@gmail.com
}

Abstrak: Tujuan penelitian ini adalah 1) Untuk meningkatkan kualitas proses pembelajaran PPKn melalui model pembelajaran kooperatif tipe Jigsaw. 2) Untuk meningkatkan hasil belajar PPKn siswa kelas VIIIA SMP Negeri 1 Binongko dapat ditingkatkan melalui model pembelajaran kooperatif tipe Jigsaw. Penelitian ini dilaksanakan di SMP Negeri 1 Binongko.

Jenis penelitian ini adalah penelitian tindakan kelas. Pelaksanaan tindakan dilaksanakan dalam dua siklus. Setiap siklus terdiri dari dua kali pertemuan. Prosedur penelitian ini meliputi:perencanaan, pelaksanaan tindakan, observasi, evaluasi, dan refleksi. Teknik pengumpulan data dalam penelitian ini menggunakan lembar observasi, dan evaluasi tes siklus. Teknik analisis data dalam penelitian ini menggunakan analisis deskriptif yaitu menghitung presentase aktivitas guru, aktivitas siswa dan ketuntasan hasil belajaar siswa selama proses pembelajaran.

Berdasarkan hasil analisis dan pembahasan, menunjukan bahwa penerapan model pembelajaran kooperatif tipe Jigsaw dapat meningkatkan pemahaman siswa pada pelajaran Pkn di kelas VIII SMP Negeri 1 Binongko. Halini dilihat dari tercapainya indikator keberhasilan baik dari segi proses maupun hasil dalam penelitian ini. Aktivitas guru pada siklus I pertemuan pertama sebesar $80 \%$ dan pertemuan kedua sebesar $86,66 \%$ meningkat pada siklus II menjadi $87 \%$ pada pertemuan pertama dan 93,33\% pertemuan kedua. Aktivitas siswa pada siklus I pertemuan pertama sebesar 60\% dan pertemuan kedua sebesar 66,66\% meningkat pada siklus II menjadi $80 \%$ pada pertemuan pertama dan 86,66 pada pertemuan kedua. Dari segi hasil yaitu hasil belajar siswa, rata-rata hasil belajar siswa pada siklus I sebesar 77,09 meningkat pada siklus II menjadi 81,46\%.

Hasil kesimpulan bahwa model pembelajaran kooperatif tipe Jigsaw dapat meningkatkan aktivitas hasil belajar siswa pada mata pelajaran Pkn pada kelas VIII SMP Negeri 1 Binongko.

\section{Kata Kunci: Hasil belajar PPKn, Model Kooperatif Tipe Jigsaw}




\title{
IMPROVING STUDENTS' ENGAGEMENT, LEARNING, AND ACHIEVEMENT THROUGH JIGSAW COOPERATIVE LEARNING MODEL
}

\author{
Muhammad Kasim,Hamuni, Irawaty, \\ Department of Civic Education \\ Faculty of Teacher Training and Education \\ Halu Oleo University \\ Email.muhammadkasim@gmail.com, \\ hamunifaturrahman@gmail.com,hijrahwaode207@gmail.com
}

\begin{abstract}
The objectives of this research are 1) To improve the quality of PPKn learning process through Jigsaw cooperative learning model. 2) To improve students' achievement at PPKn Subject of class VIIIA students of SMP Negeri 1 Binongko through Jigsaw cooperative learning model.This research was conducted at SMP Negeri 1 Binongko.

The design was classroom action research carried out in two cycles. Each cycle consisted of two meetings. The procedure of this research consisted of: planning, implementing the action, observing, evaluating and reflecting. Data collection techniques in this study used observation sheets, and evaluation cycle tests. Data analysis technique used in this study was descriptive analysis, namely calculating the percentage of teachers' activity, students' activity and students' achievement during the learning process.

Based on the results of data analysis and discussion, it showed that the use of Jigsaw cooperative learning model can improve students' understanding of material taught at class VIII of SMP Negeri 1 Binongko. It can be seen from the achievement of success indicators both in terms of process and results of this research. Teacher's activity in the first cycle of the first meeting was $80 \%$ and the second meeting was $86.66 \%$, it increased in the second cycle to $87 \%$ at the first meeting and $93.33 \%$ at the second meeting. Students' activity in the first cycle of the first meeting was $60 \%$ and the second meeting was $66.66 \%$, it increased in the second cycle to $80 \%$ at the first meeting and 86.66 at the second meeting. In terms of results, namely students' achievement, the mean score in the first cycle was 77.09 , it increased in the second cycle to $81.46 \%$.

The conclusion of this research is that Jigsaw cooperative learning model can increase students' achievementat class VIII of SMP Negeri 1 Binongko.
\end{abstract}

Keywords: PPKnStudents; Achievement; Jigsaw Cooperative Model

\section{PENDAHULUAN}

Mata Pelajaran Pendidikan Kewarganegaraan merupakan mata pelajaran yang memfokuskan pada pembentukan warga negara yang memahami dan mampu melaksanakan hak-hak dan kewajibannya untuk menjadi warga negara Indonesia yang cerdas, terampil, dan berkarakter yang diamanatkan oleh Pancasila dan UUD 1945.Guru memiliki tanggung jawab agar pembelajaran yang diberikan dapat berhasil dengan baik. Keberhasilan ini banyak bergantung kepada usaha guru membangkitkan aktivitas belajar siswa dalam mengikuti proses pembelajaran. Hal ini sejalan dengan yang dikemukakan oleh Dimyati dan Mujiono (1999:3) mengemikakan bahwa belajar itu dipandang dari dua sisi yaitu dari sisi siswa dan dari sisi guru.Aktivitas dalam belajar mengajar merupakan rangkaian kegiatan yang meliputi keaktifan siswa dalam mengikuti pelajaran, bertanya hal-hal yang belum jelas, mencatat, mendengar, 
berpikir, membaca, dan segala kegiatan yang dilakukan yang dapat menunjang prestasi belajar.

Hal ini sejalan dengan pendapat yang dikemukakan oleh Slameto (2003:32) bahwa dalam untuk mencapai tujuan belajar perlu diciptakan kondisi belajar yang kondusif agar terjadi proses belajar yang optimal dan hasil belajar yang memuaskan. Belajar sambil melakukan aktivitas lebih banyak mendatangkan hasil bagi anak didik, sebab kesan yang didapatkan oleh anak didik lebih tahan lama tersimpan di dalam benak anak didik.Pembelajaran yang efektif adalah pembelajaran yang menyediakan kesempatan belajar sendiri atau melakukan aktivitas sendiri. Proses pembelajaran yang dilakukan di dalam kelas merupakan aktivitas mentranformasikan pengetahuan, sikap, dan keterampilan Martinis Yamin, (2007:75). Aktivitas belajar merupakan aktivitas yang bersifat fisik maupun mental.Namun untuk mendapatkan hasil belajar yang memuaskan harus diperlukan upaya-upaya untuk mencapainya, misalnya melalui pembelajaran di sekolah. Dalam kegiatan pembelajaran hendaknya siswa diajak untuk berinteraksi dengan seluruh peserta belajar yang ada dalam kelas. Interaksi ini harus berlangsung secara berkesinambungan sehingga guru tidak terlalu mendominasi kegiatan pembelajaran yang berlangsung. Guru harus memberikan kesempatan kepada siswa untuk mengembangkan kemampuan berpikirnya.

Berdasarkan hasil pengamatan awal, wawancara dan hasil evaluasi pelaksanaan pembelajaran pendidikan kewarganegaraan dikelas VIIIA SMP Negeri 1 Binongko tahun pelajaran 2017/2018 diperoleh data sebagai berikut: (1) kegiatan pembelajaran masih banyak didominasi oleh guru sehingga siswa kurang aktif mengikuti pembelajaran Pendidikan Kewarganegaraan, (2) metode yang digunakan dalam pembelajaran Pendidikan Kewarganegaraan menitikberatkan pada penanaman informasi/konsep-konsep yang dipelajari diberitahukan atau disajikan dengan ceramah sehingga siswa kurang paham dengan apa yang dijelaskan guru; (3) dalam proses pembelajaran Pendidikan Kewarganegaraan siswa merasa kurang mendapatkan pengarahan dan bimbingan dalam belajar mandiri, (4) dalam pelaksnaan pembelajaran guru masih kurang memberikan kesempatan siswa untuk bertanya.Aktivitas merupakan suatu bentuk partisipasi siswa dalam pelaksanaan belajar yang dapat dilihat dari bentuk interaksi antara siswa dan interksai siswa dengan guru Suyatno,(2009). Hasil belajar siswa SMP Negeri 1 Binongko kelas VIIIA umumnya dibawah 70 sedangkan kriteria ketuntasan minimal (KKM) mata pelajaran ppkn adalah 70, motivasi belajar siswa pun rendah, sebagian siswa tidak menjawab pertanyaan guru ketika ditanya, jarang ada siswa yang bertanya kepada guru mengenai penjelasan materi yang diajarkan, ketika guru memberikan ulangan individu masih banyak siswa yang menyontek. Selain permasalahan di atas suasana kelas masih cenderung parsial artinya ada pengelompokkan siswa yang pandai dengan siswa yang kurang pandai.Berdasarkan uraian di atas terungkap bahwa Pembelajaran PKn di kelas VIIIA masih kurang berhasil, minat belajar PKn kurang dan hasil belajar siswa belum sesuai standar yang telah ditetapkan.Amri dan Ahmadi (2010:4) menyebutkan bahwa " Hasil belajar adalah hasil yang dicapai dalam suatu usaha dalam hal ini usaha belajar dalam perwujudan hasil belajar siswa. Hal ini sesuai dengan yang dikemukakan oleh Winatapura, Udin S. (2007:72), bahwa hasil belajar tidak dapat dipisahkan dari apa yang terjadi dalam kegiatan belajar baik dikelas, disekolah maupun diluar sekolah. Oleh karena itu perlu ada tindakan untuk mengatasi permasalahan pembelajaran PKn 
di kelas tersebut, yaitu dengan tetap menerapkan metode diskusi namun pelaksanaannya menggunakan Model Pembelajaran Jigsaw.

\section{METODE PENELITIAN}

Jenis penelitian ini adalah penelitian tindakan kelas (PTK), menggunakan model pembelajaran kooperatif tipe Jigsaw untuk meningkatkan kualitas pembelajaran dan hasil belajar PPKn siswa kelas VIII SMP Negeri 1 Binongko pada materi "Kedudukan dan fungsi Pancasila".Subjek dalam penelitian ini adalah seluruh siswa kelas VIII $_{\mathrm{A}}$ SMP Negeri 1 Binongko berjumlah 24 orang terdiri dari 15 orang siswa laki-laki dan 8 orang siswa perempuan. Pemilihan subjek ini didasarkan pada permasalahan yang dihadapi guru di kelas dan nilai yang diperoleh siswa masih di bawah standar nilai minimal KKM ketuntasan belajar yang ditetapkan oleh sekolah.Penelitian ini direncanakan 2 siklus dengan tetap berpedoman pada ketentuan indikator kinerja tiap siklus terdiri dari 2 kali pertemuan pembelajaran dan tes dilakukan pada akhir pertemuan kedua pada tiap siklus pembelajaran. Pelaksanaan tindakan pada setiap siklus dilakukan dengan prosedur: (1) perencanaan, (2) pelaksanaan tindakan, (3) observasi dan evaluasi, dan (4) refleksi.Data penelitian dikumpulkan dengan menggunakan lembar observasi dan tes hasil belajar

\section{HASIL PENELITIAN}

Keberhasilan mengatjar guru dihitung berdasarkan skor perolehan guru dibagi dengan skor maksimum dikaliakan seratus persen. Hasil observasi aktivitas mengajar guru pada tingkatan siklus 1 Dapat dilihat pada tabel berikut: 
Tabel 4.1 Aktivitas Guru Siklus IdanSiklus 2

\begin{tabular}{|c|c|c|c|c|c|c|}
\hline \multirow[t]{2}{*}{ No } & \multirow{2}{*}{$\begin{array}{c}\text { Kegiatan } \\
\text { Pembelajaran }\end{array}$} & \multirow[t]{2}{*}{ Aspek Yang Diamati } & \multicolumn{2}{|c|}{ Siklus 1} & \multicolumn{2}{|c|}{ Siklus 2} \\
\hline & & & P1 & $\mathbf{P 2}$ & P1 & $\mathbf{P 2}$ \\
\hline \multirow[t]{2}{*}{1} & \multirow[t]{2}{*}{$\begin{array}{l}\text { Kegiatan } \\
\text { pendahuluan }\end{array}$} & $\begin{array}{l}\text { a. Guru menjelaskan indikator/materi } \\
\text { pembelajaran yang akan dicapai dalam proses } \\
\text { pembelajaran }\end{array}$ & $\checkmark$ & $\checkmark$ & $\checkmark$ & $\checkmark$ \\
\hline & & $\begin{array}{l}\text { b. Guru memberikan pertanyaan kepada siswa } \\
\text { tentang memahami kedudukan dan fungsi } \\
\text { Pancasila }\end{array}$ & $\checkmark$ & $\checkmark$ & 0 & $\checkmark$ \\
\hline \multirow[t]{10}{*}{2} & \multirow[t]{10}{*}{ Kegiatan inti } & $\begin{array}{l}\text { a. Guru mengarahkan siswa untuk menyiapkan } \\
\text { bahan yang akan didiskusikan }\end{array}$ & $\checkmark$ & $\checkmark$ & $\checkmark$ & $\checkmark$ \\
\hline & & $\begin{array}{l}\text { b. Guru mengelompokan siswa yang terdiri dari } \\
5 \text { atau } 6 \text { orang siswa yang heterogen. }\end{array}$ & $\checkmark$ & $\checkmark$ & $\checkmark$ & $\checkmark$ \\
\hline & & $\begin{array}{l}\text { c. Guru menjelaskan materi kedudukan dan } \\
\text { fungsi Pancasila. }\end{array}$ & 0 & $\checkmark$ & 0 & $\checkmark$ \\
\hline & & $\begin{array}{l}\text { d. Guru membagi LKS kepada masing-masing } \\
\text { kelompok. }\end{array}$ & $\checkmark$ & $\checkmark$ & $\checkmark$ & $\checkmark$ \\
\hline & & $\begin{array}{l}\text { e. Guru meminta setiap kelompok } \\
\text { menyelesaikan soal-soal LKS. }\end{array}$ & $\checkmark$ & $\checkmark$ & $\checkmark$ & $\checkmark$ \\
\hline & & $\begin{array}{l}\text { f. Guru memantau kerja dari kelompok selama } \\
\text { diskusi berjalan }\end{array}$ & $\checkmark$ & $\checkmark$ & $\checkmark$ & $\checkmark$ \\
\hline & & $\begin{array}{l}\text { g. Guru meminta wakil dari tiap kelompok } \\
\text { mempersentasikan sub bab mereka. }\end{array}$ & 0 & $\checkmark$ & $\checkmark$ & $\checkmark$ \\
\hline & & $\begin{array}{l}\text { h. Guru memberikan kesempatan kepada } \\
\text { kelompok lain untuk menanggapi } \\
\text { pekerjaannya temannya. }\end{array}$ & $\checkmark$ & $\checkmark$ & 0 & $\checkmark$ \\
\hline & & $\begin{array}{l}\text { i. Guru memberi skor untuk masing-masing } \\
\text { kelompok sesuai dengan jawaban mereka. }\end{array}$ & 0 & $\checkmark$ & $\checkmark$ & $\checkmark$ \\
\hline & & $\begin{array}{l}\text { j. Guru memberikan penghargaan pada setiap } \\
\text { kelompok yang telah selesai } \\
\text { mempersentasikan laporannya. }\end{array}$ & $\checkmark$ & 0 & $\checkmark$ & $\checkmark$ \\
\hline \multirow[t]{2}{*}{3} & \multirow[t]{2}{*}{$\begin{array}{l}\text { Kegiatan penutup/ } \\
\text { akhir }\end{array}$} & $\begin{array}{l}\text { a. Guru membimbing siswa merangkum materi } \\
\text { pembelajaran yang telah dibahas bersama. }\end{array}$ & $\checkmark$ & $\checkmark$ & $\checkmark$ & $\checkmark$ \\
\hline & & b. Guru memberikan tugas rumah & $\checkmark$ & $\checkmark$ & $\checkmark$ & 0 \\
\hline \multicolumn{2}{|c|}{ Total } & & 12 & 13 & 13 & 14 \\
\hline \multicolumn{2}{|c|}{ Skor rata-rata } & & \multicolumn{2}{|c|}{12.5} & \multicolumn{2}{|c|}{13.5} \\
\hline \multicolumn{2}{|c|}{ Persentase } & & \multicolumn{2}{|c|}{$83.33 \%$} & \multicolumn{2}{|c|}{$90 \%$} \\
\hline
\end{tabular}

Sumber: data hasil observasi

Berdasarkan Tabel 4.1 di atas, terlihat bahwa skor perolehan aktivitas guru siklus 1 pertemuan pertama adalah 12 dan pertemuan kedua adalah 13 . Keberhasilan aktivitas mengajar guru dihitung berdasarkan skor perolehan guru dibagi dengan skor maksimum dikalikan seratus persen hingga presentase keberhasilan aktivitas guru siklus I pertemuan pertama adalah 80 dan pertemuan kedua adalah 87. Rata-rata dari kedua pertemuan tersebut sebesar 83,5.Sedangkansiklus 2 terlihat bahwa skor perolehan aktivitas mengajar guru siklus II pertemuan pertama adalah 11 pertemuan kedua adalah 14, atau perolehan rata-rataaktivitas guru siklus II sebesar 12,5 bila dipersentase hasil \% sebesar 
83,3\%. Keberhasilan Aktivitas Mengajar Guru dihitung berdasarkan skor perolehan siswa dibagi dengan skor maksimum dikalikan seratus persen hingga presentase keberhasilan Aktivitas Mengajar Guru siklus II pertemuan pertama adalah 73 dan pertemuan kedua adalah 93. Rata-rata dari kedua pertemuan tersebut sebesar 90 .

Aktivitas siswa selama pembelajaran berlangsung diamati oleh observer dengan menggunakan lembar observasi aktivitas siswa. Hal-hal yang harus di observasi pada pelaksanaan tindakan siklus 1 adalah respon/aktivitas siswa selama mengikuti pembelajaran yang diterapkan oleh guru dengan menggunakan model pembelajaran kooperetif tipe Jigsaw. Keberhasilan aktivitas belajar siswa dihitung berdasarkan skor perolehan guru dibagi dengan skor maksimum dikalikan seratus persen. Hasil aktivitas belajar siswa pada tindakan siklus 1dapat dilihat pada tabel berikut:

Tabel 4.2 Hasil Observasi Aktivitas Belajar Siswa Siklus 1 dansiklus2

\begin{tabular}{|c|c|c|c|c|c|c|}
\hline \multirow[t]{2}{*}{ No } & \multirow{2}{*}{$\begin{array}{c}\text { Kegiatan } \\
\text { Pembelajaran }\end{array}$} & \multirow[t]{2}{*}{ Aspek Yang Diamati } & \multicolumn{2}{|c|}{ Siklus 1} & \multicolumn{2}{|c|}{ Siklus 2} \\
\hline & & & P1 & P2 & P1 & P2 \\
\hline \multirow[t]{3}{*}{1} & \multirow[t]{3}{*}{$\begin{array}{l}\text { Kegiatan } \\
\text { pendahuluan }\end{array}$} & $\begin{array}{l}\text { a. Siswa menyimak penjelasan guru tentang } \\
\text { indikatio/materi pelajaran yang akan } \\
\text { dicapai. }\end{array}$ & $\checkmark$ & $\checkmark$ & $\checkmark$ & $\checkmark$ \\
\hline & & b. $\quad$ Siswa menjawab pertanyaan guru. & $\checkmark$ & $\checkmark$ & 0 & $\checkmark$ \\
\hline & & $\begin{array}{l}\text { c. Siswa menyiapkan bahan yang akan } \\
\text { didiskusikan }\end{array}$ & 0 & $\checkmark$ & $\checkmark$ & $\checkmark$ \\
\hline \multirow[t]{10}{*}{2} & \multirow[t]{10}{*}{ Kegiatan inti } & $\begin{array}{l}\text { a. Siswa membentuk kelompok yang terdiri } \\
\text { dari } 5 \text { atau } 6 \text { orang siswa yang heterogen. }\end{array}$ & $\checkmark$ & $\checkmark$ & $\checkmark$ & $\checkmark$ \\
\hline & & $\begin{array}{l}\text { b. Siswa memperhatiakan penjelasan guru } \\
\text { tentang kedudukan dan fungsi Pancasila. }\end{array}$ & 0 & 0 & 0 & $\checkmark$ \\
\hline & & c. Siswa meproleh LKS yang diberikan guru. & $\checkmark$ & $\checkmark$ & $\checkmark$ & $\checkmark$ \\
\hline & & $\begin{array}{l}\text { d. Kelompok siswa menyelesaikan soal-soal } \\
\text { LKS yang diberikan guru. }\end{array}$ & $\checkmark$ & $\checkmark$ & $\checkmark$ & $\checkmark$ \\
\hline & & e. Siswa mengerjakan LKS & $\checkmark$ & 0 & 0 & $\checkmark$ \\
\hline & & $\begin{array}{l}\text { f. Wakil dari kelompok siswa menuju di } \\
\text { depan kelas. }\end{array}$ & $\checkmark$ & $\checkmark$ & $\checkmark$ & $\checkmark$ \\
\hline & & $\begin{array}{ll}\text { g. Kelompok siswa menanggapi pekerjaannya } \\
\text { temannya. }\end{array}$ & 0 & $\checkmark$ & $\checkmark$ & $\checkmark$ \\
\hline & & h. Kelompok siswa diberikan nilai oleh guru & $\checkmark$ & $\checkmark$ & $\checkmark$ & $\checkmark$ \\
\hline & & $\begin{array}{l}\text { i. Siswa termotivasi dengan nilai yang telah } \\
\text { diberikan guru. }\end{array}$ & 0 & 0 & 0 & $\checkmark$ \\
\hline & & j. pembelajaran yang telah dibahas bersama. & 0 & 0 & $\checkmark$ & $\checkmark$ \\
\hline \multirow[t]{2}{*}{3} & \multirow[t]{2}{*}{$\begin{array}{l}\text { Kegiatan penutup/ } \\
\text { akhir }\end{array}$} & $\begin{array}{l}\text { a. Siswa merangkum materi pembelajaran } \\
\text { yang telah dibahas bersama. }\end{array}$ & 0 & 0 & $\checkmark$ & 0 \\
\hline & & $\begin{array}{l}\text { b. Siswa menyalin/menandai tugas-tugas } \\
\text { rumah. }\end{array}$ & $\checkmark$ & $\checkmark$ & $\checkmark$ & $\checkmark$ \\
\hline \multicolumn{3}{|c|}{ Total } & 9 & 10 & 12 & 14 \\
\hline \multicolumn{2}{|c|}{ skor rata-rata } & & \multicolumn{2}{|c|}{9.5} & \multicolumn{2}{|c|}{13} \\
\hline \multicolumn{3}{|c|}{ Persentase } & \multicolumn{2}{|c|}{$63.33 \%$} & \multicolumn{2}{|c|}{$86.66 \%$} \\
\hline
\end{tabular}

Sumber: data hasil observasi 
Berdasarkan Tabel 4.2 di atas, terlihat bahwa skor perolehan aktivitas belajar siswa siklus 1 pertemuan pertama adalah 9 dan pertemuan kedua adalah 10 . Keberhasilan aktivitas belajar siswa dihitung berdasarkan skor perolehan siswa dibagi dengan skor maksimum dikalikan seratus persen hingga presentase keberhasilan aktivitas belajar siswa siklus I pertemuan pertama adalah 60 dan pertemuan kedua adalah 67. Rata-rata dari kedua pertemuan tersebut sebesar 63,5.sedangkansiklus 2 terlihat bahwa skor perolehan Aktivitas belajar siswa siklus II pertemuanpertama adalah 12 dan pertemuan kedua adalah 14. Dengan demikian persentase aktivitas belajar siswa siklus II sebesar 86,6 \% dibulatkan $87 \%$. Keberhasilan aktivitas belajar siswa dihitung berdasarkan skor perolehan siswa dibagi dengan skor maksimum dikalikan seratus persen hingga presentase keberhasilan aktivitas belajar siswa siklus II pertemuan pertama 80 dan pertemuan kedua adalah 93. Rata-rata dari kedua pertemuan tersebut sebesar 87.

\section{HASIL BELAJAR SISWA}

Seorang pendidik dikatakan berhasil jika pada suatu proses belajar mengajar dapat meningkatkan hasil belajar siswa. Hasil belajar adalah kemampuan yang dimiliki siswa setelah menerima suatu tahapan pencapaian pengalaman belajar. Berdasarkan data hasil belajar siswa secara umum pada penelitian tindakan kelas dengan menerapkan model pembelajaran kooperatif tipe jigsaw dikelas VIII SMP Negeri 1 Binongko terjadi peningkatan hasil belajar siswa di setiap siklus.

Gambar 4.5. Grafik PerbandinganHasil Belajar Siswa Siklus I dan Siklus II

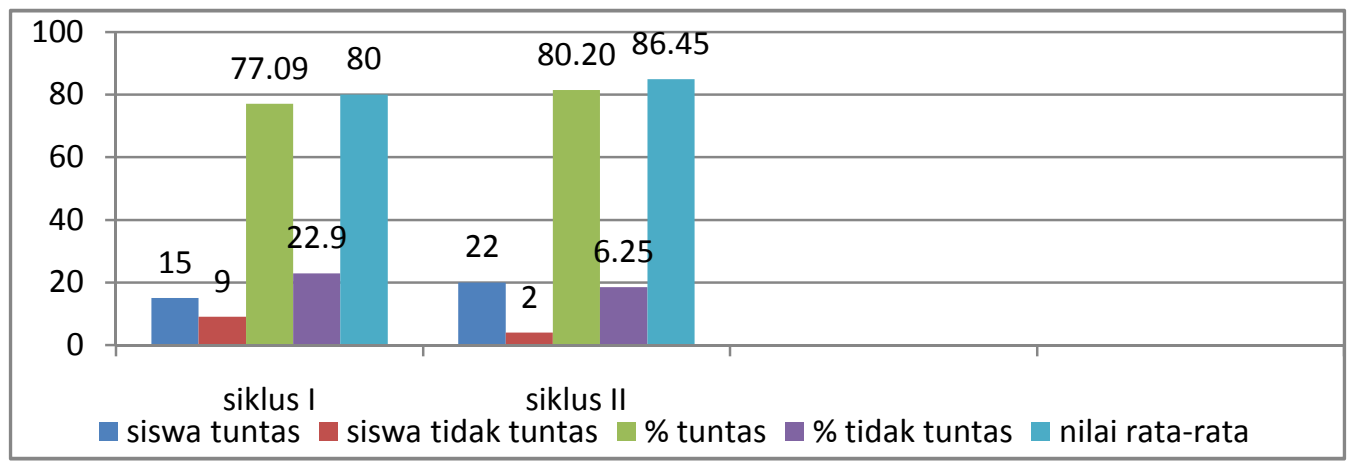

Berdasarkan gambar 4.5. di atas, menunjukan bahwa pada siklus I persentase ketuntasan hasil belajar siswa sebesar $60 \%$ atau sebanyak 15 siswa dari 24 siswa dengan nilai rata-rata 80. Pada siklus II persentase ketuntasan hasil belajar siswa meningkat sebesar 80 menjadi 80,20 atau sebanyak 22 siswa dari 24 siswa dengan nilai rata-rata sebesar 86,45. Ketuntasan belajar siswa mengindikasikan bahwa indikator keberhasilan penelitian yang telah ditetapkan telah tercapai.Rendahnya persentase ketuntasan hasil belajar siswa siklus I menunjukan indikator keberhasilan siklus I sebesar $85 \%$ belum mencapai, sehingga dilakukan perbaikan-perbaikan utamanya kinerja guru dalam menumbuhkan minat dan motivasi belajar siswa serta dalam membimbing siswa. Selain itu ketidaktuntasan beberapa siswa tersebut diakibatkan kurangnya fasilitas pembelajaran (buku) yang tersedia.Persentase ketuntasan hasil belajar siswa pada siklus II telah mencapai indikator kinerja yang ditetapkan yaitu minimal $85 \%$ 
siswa memperoleh nilai 86,45 . Meskipun masih ada 2 orang $(6,25)$ siswa yang hingga pelaksanaan tes tindakan kelas siklus II berakhir masih memiliki hasil belajar dibawah 80 , akan tetapi mereka sudah memberikan penghargaan dan sikap yang positif pada saat model pembelajaran kooperatif tipe Jigsaw diterapkan. karena indikator keberhasilan dalam penelitian ini telah tercapai maka, hipotesis tindakan dalam penelitian ini telah tercapai yaitu meningkatkan aktivitas belajar, pembelajaran, dan hasil belajar PPKn siswa kelas VIII SMP Negeri 1 Binongko melalui model pembelajaran kooperatif tipe Jigsaw.

\section{PEMBAHASAN}

\section{Aktivitas Mengajar Guru}

Aktivitas guru mengalami peningkatan pada setiap siklus karena dalam proses pembelajaran, guru melaksanakan proses belajar mengajar dengan perbaikan-perbaikan yang dilakukan dari hasil refleksi siklus sebelumnya.Pada proses pembelajaran ini, peran guru sudah maksimal dalam menerapkan model kooperatif tipe Jigsaw, karena guru telah banyak melakukan perbaikan-perbaikan dari kelemahan-kelemahan yang terjadi pada siklus sebelumnya sehingga adanya peningkatan terhadap proses pembelajaran yang diterpkan. Guru telah berhasil membimbing dan mengorganisir siswa dalam melakukan diskusi sehingga terjadi interaksi antara guru dengan siswa dan antara siswa dengan siswa.Rendahnya aktivitas mengajar guru pada siklus I diakibatkan oleh beberapa aktivitas guru dalam pembelajaran yang masih kurang seperti dalam memotivasi siswauntuk mengikuti pelajaran, membimbing siswa pada saat melakukan diskusi. Selain itu dditemukan aktivitas guru yang kurang memberi penguatan dan penghargaan kepada siswa yang memberikan pertanyaan/menanggapi pertanyaan dalam kelompok yang kinerjanya bagus, sehingga berpengaruh terhadap aktivitas dan hasil belajar siswa.

2. Aktivitas Belajar Siswa

Dari hasil analisis lembar observasi, aktivitas siswa mengalami peningkatan setiap siklus. Peningkatan keaktifan siswa ini disebabkan karena siswa telah dapat menyesuaikan dan terbiasa dengan model pembelajaran kooperatif tipe Jigsaw, sehingga proses pembelajaran menjadi semakin lebih baik sesuai dengan yang diharapkan dan siswa telah sepenuhnya terlibat aktif dalam proses pembelajaran.Dalam penelitian ini,siswa dibagi dalam 4 kelompok.Setiap kelompok terdiri dari 5-6 orang. Pembentukan kelompok dilakukan dengan mempertimbangkan perbedaan kemampuan serta jenis kelamin. Aktivitas siswa dalam proses pembelajaran berdampak langsung terhadap pencapaian hasil belajar siswa setelah pembelajaran.

3. Hasil Evaluasi

Hasil evaluasi menunjukan bahwa usaha dan keberhasilan belajar dipengaruhi oleh berbagai faktor yaitu: Karena indikator keberhasilan dalam penelitian ini telah tercapai dalam hal ini aktivitas belajar siswa selam proses pembelajaran sudah cukup baik dan minimal $85 \%$ siswa telah memperoleh nilai $\geq 80$, maka hipotesis tindakan dalam penelitian ini telah tercapai yaitu penerapan model pembelajaran kooperatif tipe jigsaw dapat meningkatkan kualitas proses pembelajaran PPKn siswa kelas VIII SMP Negeri 1 Binongko melalui model pembelajaran kooperatif tipe jigsaw. 


\section{PENUTUP}

\section{Kesimpulan}

berikut :

Berdasarkan hasil penelitian dan pembahasan dapat di simpulkan sebagai

1. Aktivitas yang ditunjukan oleh siswa dalam pembelajaran dengan menggunakan model pembelajaran kooperatif tipe Jigsaw menunjukan peningkatan yang baik dimana keterlaksanaan skenario pembelajaran aktivitas mengajar guru dari siklus I ke siklus II menunjukan peningkatan, dimana tahapan pembelajaran pada siklus I pada pertemuan pertama terlaksana adalah $60 \%$ dan pada pertemuan kedua $66,66 \%$. Kemudian pada siklus II pertemuan pertama terlaksana $80 \%$ dan pertemuan kedua terlaksana $86,66 \%$.

2. Aktivitas yang ditunjukan oleh guru dalam pembelajaran dengan menggunakan model pembelajaran kooperatif tipe Jigsaw meninjukan peningkatan yang baik dimana keterlaksanaan skenario pembelajaran aktivitas mengajar guru dari siklus I ke siklus II menunjukan peningkatan. Hal ini dapat dilihat pada siklus I pertemuan pertama $80 \%$ dan pada pertemuan kedua $86,66 \%$. Kemudian pada siklus II pertemuan pertama 73,33\% dan pertemuan kedua 93,33\%.Hasil belajar Pkn siswa kelas VIII SMP Negeri 1 Binongko dapat ditingkatkan melalui penerapan model pembelajaran kooperatif tipe Jigsaw. Hal ini dapat dilihat dari nilai rata-rata pada siklus I mencapai 77,09 dan pada siklus II sebesar 86,45. Pelaksanaan tindakan dikatakan berhasil karena telah mencapai indikator kinerja yang telah ditetapkan.

\section{Saran}

Berdasarkanhasilpenelitian yang telah di capai maka dapat diberikan saransaran sebagai berikut:

1. Diharapkan kepada guru agar menerapkan model pembelajaran kooperatif tipe Jigsaw dalam upaya meningkatkan aktivitas belajar, pembelajaran, dan hasil belajar PPKn siswa karena dalam penelitian ini model pembelajaran kooperatif tipe Jigsaw dapat meningkatkan hasil belajar siswa.

2. Diharapkan kepada semua guru dalam menerapkan model pembelajaran kooperatif tipe Jigsaw dalam pembagisn kelompok harus memperhatikan tingkat kemampuan siswa.

\section{Daftar Pustaka}

Amri, S. Dan Ahmadi K. I. 2010. Proses Pembelajaran Kreatif Dan Inovatif Dalam Kelas. Jakarta : Prestasi Pustaka Raya.

Dimyati dan Mudjiono. 1999. Belajar Dan Pembelajaran. Jakarta: Rineka Cipta.

Martinis, Yamin. 2013. Strategi dan Metode Dalam Model Pembelajaran.Jakarta: GP Press group.

Martinis, Yamin. 2007. KiatPembelajaranSiswa. Jakarta. Gaungpersada press.

Slameto. 2003. Belajar dan Faktor-Faktor yang Mempengaruhinya. Jakarta: Rineka Cipta.

Suyatno. 2009. Menjelajah pembelajaran inivatif. Sidoarjo: Masmedia Buana Pustaka.

Winatapura, Udin S. ddk. 2007. Teori-Teori Belajar dan Pembelajaran. Jakarta: Universitas Terbuka 